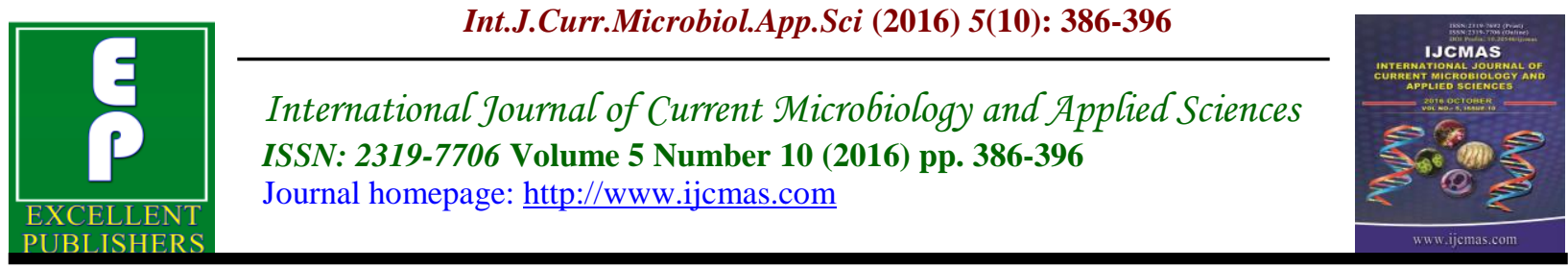

Original Research Article

http://dx.doi.org/10.20546/ijcmas.2016.510.044

\title{
Bioremediation of Poly Aromatic Hydrocarbons (PAHs) and Crude Oil by Fungal Consortium from West Coast of Karnataka, India
}

\author{
S.V. Praveen Kumar, B.K. Manjunatha*, Pavani Bhat, R. Veena, \\ Swetha S. Pawate and M. Yogashree \\ Department of Biotechnology, The Oxford College of Engineering, \\ Bengaluru-560068 Karnataka, India \\ *Corresponding author
}

\section{Keywords}

Bioremediation, Fungi,

West Coast,

PAHs,

Crude oil, GC-MS.

\section{Article Info}

Accepted:

14 September 2016

Available Online:

10 October 2016

\section{A B S T R A C T}

The present study primarily aims at developing an effective fungal consortium for the bioremediation of Poly Aromatic Hydrocarbons (PAHs) and crude oil. The hydrocarbon utilization capabilities of the potent isolated strains were studied for test hydrocarbons like benzene, toluene, naphthalene, paraffin and crude oil as model hydrocarbons for a period of 10 days. Degradation process was assessed by measuring percentage of TPH in residual oil, biological oxygen demand (BOD), chemical oxygen demand (COD), total plate count, UV spectrophotometric analysis and GC-MS studies. The study revealed that, among 45 isolated strains from PAHs/crude oil contaminated soil; four strains showed maximum degradation of crude oil \& PAHs.18s rRNA sequencing was used to identify the strains and, was identified as Aspergillus terreus, Aspergillus aculeatus, Scedosporium boydii and Aspergillus sp. The degradation process for this consortium was further optimized using Response Surface Method (RSM). The fungal isolates were also screened for biosurfactant production, Immobilization of the isolates on sodium alginate beads will be used as model of bioremediation studies.

\section{Introduction}

Increase in industrialization and other derogatory anthropogenic activities have led to elevated releases of dangerous compounds. Prevalent contaminants include petroleum hydrocarbons (PHCs), polycyclic aromatic hydrocarbons (PAHs), halogenated hydrocarbons, pesticides, solvents, metals, and salt. Polycyclic aromatic hydrocarbons (PAHs) are some of the most toxic pollutants that have been accumulated in the environment by natural and anthropogenic activities (Obahiagbon et al., 2014). They are mainly produced from incomplete combustion of organic materials, fossil fuels, spillage of petroleum products and various industrial activities (Dasaria et al., 2014). PAHs have been identified as hazardous chemicals by different State and Central Pollution Control Boards, because of their toxic, carcinogenic and mutagenic effects on living body (Bisht et al., 2015; Igiehon et al., 2015; Balaji et al., 2013; Sayara et al., 2011). 
The hydrocarbon fuels contain an excessive quantity of PAHs, utilization of which causes abundant distribution and retention of the same in the ecosphere (Antizar-Ladislao et al., 2006; Weissenfiels et al., 1992; Manilal and Alexander, 1991). These PAHs are considered as the most frequent organic pollutant of environment and are classified as hazardous wastes due to their cytotoxic, mutagenic and carcinogenic effects on human (Rahman, 2002; Margesin, 2003). $\mathrm{TPH}$ in the environment are toxic to both animals and humans and can affect the liver, lungs, kidneys and nervous system, leading to cancer as well as having immunological and reproductive effects (Rushton et al., 2007). Hence strategies to detoxify the PAHs is the need of the day. PAHs pollution can be removed using other conventional techniques viz., chemical and physical method, where these methods are expensive and normally require the addition of more chemicals, energy or the removal of large areas of polluted land, which can be damaging to the surrounding ecosystem (Ravikrishna et al., 1998).

Bioremediation is the use of microorganisms that are capable of utilizing the contaminant hydrocarbons as energy sources, thus leading to their degradation and clean up in the environment (Karimi et al., 2015; Vanishree et al., 2014; Hadibarata et al., 2009). In this process microorganisms convert hazardous pollutants into less toxic compounds. Biodegradation involves mineralization of organic constituents to the soluble inorganic compounds or to transform organic constituents to other soluble organic compounds (Kumar et al., 2015, Chandran and Das, 2011). Bioremediation is said to be efficient, inexpensive and environmentally safe cleanup for waste. Although many species of bacteria and algae have been found to be efficient in degradation of low molecular weight hydrocarbons, for degradation of high molecular weight hydrocarbons, fungal species are preferred (Potin et al., 2004). This is because; the use of fungi is economical since they grow on inexpensive substrates like forest and agricultural wastes (George-okafor et al., 2009). Also, fungi have the ability to produce many extracellular enzymes that can degrade a range of hydrocarbons (Vanishree et al., 2014). Hence, development of bioremediation tool which could be; cost effective, environmental friendly, highly efficient will help in the amelioration of PAHs in aquatic and terrestrial habitat.

\section{Materials and Methods}

\section{Sample collection}

The PAHs/crude oil contaminated soil samples were collected from different localities of coastal Karnataka. The coordinates for the location from which the soil samples were collected are: $12.8700^{\circ} \mathrm{N}$, $74.8800^{\circ}$ E. About 10 grams of each sample was collected from a depth of $1-5 \mathrm{~cm}$, transferred to a plastic container using sterile spatula, and tightly sealed and transported to the lab and further processed (Stephen et al., 2014; Al-Nasrawi, 2012).

\section{Isolation and maintenance of pure culture}

To enhance the number of indigenous microorganisms capable of hydrocarbon degradation, enrichment procedure as described by Nwachukwu (2000) was followed. $1 \mathrm{~g}$ of each of the soil samples were added to FSM taken in culture bottles containing $50 \mathrm{~mL}$ of media. $2 \%$ crude oil was used as carbon source. These bottles were incubated for a minimum of 10 days, at room temperature (Senthilkumaran et al., 2015). Each of the soil samples were serially diluted and plated on Potato Dextrose Agar 
(PDA) plates (Chaudhry et al., 2012). After the incubation period, the growth of multiple colonies of fungi was observed. From these plates, non-repetitive single colonies were isolated onto fresh PDA slants for fungal isolation. These slants were stored at $4^{\circ} \mathrm{c}$ till further use.

\section{Identification of fungal isolates}

18S rRNA sequencing technique was employed to identify the potent fungal isolates. The fungal genomic DNA was isolated using the Insta Gen ${ }^{\mathrm{eTM}}$ Matrix Genomic DNA isolation kit. Using $18 \mathrm{~S}$ rRNA ITS region universal primers gene fragment was amplified using MJ Research PTC-225 Peltier Thermal Cycler. Sequencing reactions was performed using a ABI-PRISM BigDye ${ }^{\mathrm{TM}}$ Terminator Cycle Sequencing Kits with AmpliTAq DNA Polymerase (FS enzyme) (Applied Biosystems). The 18S rRNA sequence was blast using NCBI blast similarity search tool. Finally, the program PhyML 3.0aLRT was used for Phylogenetic analysis.

\section{Preparation of Fungal Consortium}

Fungal consortium was prepared according to the method followed by Rahman 2002, with minor modifications. The spore suspensions of each potent isolates were prepared separately by scraping the spores aseptically from the pre-gowned mass culture on PDA.

To make the consortium, the each prepared fungal spore suspension was mixed thoroughly in equal volumes and inoculated onto $250 \mathrm{~mL}$ shake flasks containing $100 \mathrm{ml}$ FSM and incubated at $25^{\circ} \mathrm{C}$ at $200 \mathrm{rpm}$ for 12 hours. The prepared spore suspension of fungal consortium was used as inoculum for further degradation of crude oil and PAHs.

\section{Preliminary degradation studies}

The method of Youseff et al., (2010) was adopted for the biodegradation studies. Fungal spore suspension was prepared and inoculated into FSM broth incorporated with sterile $2 \%$ crude oil and redox indicator $2 \%$ DCPIP. The uninoculated flask serves as control. The flasks were incubated at $30^{\circ} \mathrm{C}$ with constant shaking at a $180 \mathrm{rpm} / \mathrm{min}$ for 10 days. The aliquots in the flasks were monitored daily for color change (from deep blue to colorless).

\section{PAHs and Crude Oil Utilization Studies}

Each of the potential fungal strains obtained from the preliminary degradation studies were inoculated to full strength media containing $2 \%$ different PAHs viz., benzene, toluene, naphthalene, paraffin and crude oil collected from ONGC as model hydrocarbons.

The flasks were incubated at $30{ }^{\circ} \mathrm{C}$ in an orbital shaker at $180 \mathrm{rpm}$ for 10 days. The PAHs and crude oil utilization by the fungal isolates and consortium was confirmed by $\%$ TPH analysis, total plate count, BOD, COD level using the standard protocol and by UV spectrophotometric studies at regular intervals of time $\left(0^{\text {th }}, 2^{\text {nd }}, 4^{\text {th }}, 6^{\text {th }}, 8^{\text {th }}\right.$ and $10^{\text {th }}$ day) respectively.

\section{Assessment of crude oil and PAHs Degradation by fungal isolates}

\section{Biomass estimation}

The change in the yield/biomass of the each fungal strains and consortium was estimated gravimetrically. The flask weight was taken before and after incubation period at regular intervals of incubation period. 
Biological Oxygen Demand (BOD) and Chemical Oxygen Demand (COD) analysis

In order to assess the rate of degradation and PAHs utilization by the isolate PM-1, the BOD \& COD analysis were performed by following standard methods (APHA, $2001 \&$ IS-3025).

\section{Total Petroleum Hydrocarbon (\% TPH) analysis}

Residual oil was extracted by adding hexane to equal volume of broth culture and shaking thoroughly as described by Obayori et al., 2009 after removing the aqueous phase with separating funnel. The residual oil concentration of the after treatment and before treatment using the fungal isolates and consortium was determined, $\%$ of Total Petroleum Hydrocarbon (TPH) by gravimetrically and results were expressed as percentages of respective controls (Kumar \& Manjunatha, 2015).

\section{Analysis of PAHs/ crude oil degradation through GC-MS}

The extracted residual crude oil/PAHs were used to detect the components left after the degradation study using the method employed by Pasumarthi et al., 2013 with slight modifications. The mixture was stirred vigorously on a magnetic stirrer for $15 \mathrm{~min}$ and centrifuged at $2000 \mathrm{~g}$ for $5 \mathrm{~min}$. The lower organic phase was collected carefully using a micropipette and was condensed at $28 \mathrm{rpm}$ and $40{ }^{\circ} \mathrm{C}$ until the hexane was evaporated. The dried crude oil sediment was collected by adding $1 \mathrm{ml}$ of hexane and then dehydrated in a column with $2 \mathrm{~g}$ anhydrous $\mathrm{Na}_{2} \mathrm{SO}_{4}$. The oil content in the sample was determined by gravimetric analysis by using $0.5 \mathrm{ml}$ of the eluent and carefully evaporated until dry. An aliquot
$(10 \mathrm{mg})$ of the eluent was cleaned by passing it through $2 \mathrm{~g}$ of $\mathrm{Al}_{2} \mathrm{O}_{3}(5 \% \mathrm{w} / \mathrm{w}$ deactivated), concentrated and exchanged with hexane $(1.0 \mathrm{ml})$ by gentle solvent evaporation under a stream of nitrogen gas. The GC-MS analysis was performed using a 7890A gas chromatograph (Agilent Technologies), fitted with a HP-5 MS (30 m $0.25 \mathrm{~mm}$ i. d., $0.25 \mathrm{~lm}$ film) capillary column (J\&W Scientific, Folsom, CA USA) coupled to a 5975C MS spectrometer equipped with a triple axis detector (Agilent Technologies). The initial column temperature was held for $1 \mathrm{~min}$ at $60^{\circ} \mathrm{C}$, followed by an initial ramp up rate of $15{ }^{\circ} \mathrm{C}$ per minute to $150{ }^{\circ} \mathrm{C}$ and then $6{ }^{\circ} \mathrm{C}$ per minute to a final temperature of $320{ }^{\circ} \mathrm{C}$, as previously reported (Jimenez et al., 2012). Data were acquired in the full screen mode from 510 to 490 units with 5 min of solvent delay and processed by the Agilent Chemstation software.

\section{Results and Discussion}

\section{Isolation and identification of isolates}

From the soil samples, total of 45 fungal strains were isolated and checked for the crude oil/PAHs utilization ability. Among the obtained isolates 4 best fungal strains (K-08, K-12, K-25 \& K-43) were selected for the present study, The isolates were identified as, Aspergillus sp., Aspergillus terreus, Aspergillus aculeatus and Scedosporium boydii respectively using $18 \mathrm{~s}$ r RNA sequencing (Table-1 \& Fig.1)

\section{Performance of the isolated fungal strains to utilize PAHs \& crude oil}

The obtained isolates were checked for the utilization capability of PAHs \& crude oil as sole carbon source using DCPIP method, where out of 45 fungal isolates, 15 fungal strains were selected for further degradation 
studies based on their ability to produce a color change in the media from blue to colorless.

The selected 15 isolates were further subjected for the degradation of Naphthalene, Benzene, Toluene, Liquid Paraffin and Engine oil and Crude oil as model poly aromatic hydrocarbons. From the degradation studies, four best performers; Aspergillus sp. (K-08), Aspergillus terreus (K-12), Aspergillus aculeatus (K-25) and Scedosporium boydii (K-43) were selected based on their degradation capability, ability to produce surfactant and faster degradation in full strength media at $10^{\text {th }}$ day of incubation.

Based on their co-existing nature and biodegradation performance, the four strains were clubbed together to make the consortium and used for degradation studies, which showed the effective degradation by reducing the time taken by individual strains by 10 days to 6 days and degrade most of the toxic metabolites of PAHs and crude oil.

\section{Assessment of rate of degradation}

After incubation, the degradation performance by both individual and consortium was assessed using following methods,

Visual observation: The presence of the crude oil/PAHs in the test as well as in control sample was visualized. The change in the nature (emulsification) of the crude oil/PAHs was recorded at regular intervals of time. Where out of 15 tested fungi sample, 4 strains viz., K-08, K-12, K-25 and $\mathrm{K}-43$ shows the, richer emulsification due to the enzyme activity and presence of biosurfactants (Figure-2a, 2b \&2c). After the incubation period, the biomass was increased significantly, indicating the affinity of the test organism to use hydrocarbon as sole carbon/energy source.

Accumulation of the fungal mat was observed under treatment with PAH's which is in correlation with and biomass estimated gravimetrically. It was observed that, degradation capacity of the individual strains was less than $70 \%$ for all test hydrocarbons by 4 isolates.

However the consortium showed more than $70 \%$ degradation for all test hydrocarbons. Degradation percentage was seen to be greater than that of individual performance for 6 days. $67.58 \%, 76.83 \%, 75 \%, 61.5 \%$ and $72 \%$ of Crude oil, Benzene, Toluene, Naphthalene and Paraffin were degraded respectively by consortium culture in 6 days.

\section{BOD \& COD analysis}

The results showed that, BOD and COD levels decrease as the incubation time increases from day 6 to day 10. This is because these organisms utilizes hydrocarbon as the energy source, and as incubation time increases, the hydrocarbon level decreases, thus reducing the available carbon source. The BOD and COD values for the consortium were found to be 315.4 $\mathrm{mg} / \mathrm{mL}$ and $143.5 \mathrm{mg} / \mathrm{Ml}$ respectively at the $10^{\text {th }}$ day of incubation. With correspondence to the BOD and COD values, the total plate count also increases with respect to the time duration.

\section{Estimation of \% TPH for the residual PAHs \& crude oil}

The percent of TPH was analysed gravimetrically, at two days intervals of time, where the residual PAHs were estimated. The consortium shows up to $90 \%$ of the PAHs within $10^{\text {th }}$ days of incubation (Fig.3). 
Table.1 Sequence-based Identification of best fungal isolates

\begin{tabular}{|l|l|l|l|l|}
\hline No. & Isolation Code & closely related fungal isolate & Identity & Coverage \\
\hline 1 & K-08 & Aspergillus Sp. KM401402.1 & $94 \%$ & $1131 / 1880$ \\
\hline 2 & K-12 & Aspergillus terreus KF554499.1 & $100 \%$ & $1002 / 1427$ \\
\hline 3 & K-25 & Aspergillus aculeatus KJ862074.1 & $96 \%$ & $1059 / 2484$ \\
\hline 4 & K-43 & Scedosporium boydii KM461120.1 & $98 \%$ & $1059 / 1059$ \\
\hline
\end{tabular}

Table.2 GC-MS analysis: Assessment of biodegradation of Crude oil by fungal consortium after 10th day of incubation reveals degradation of major hydrocarbon moieties

\begin{tabular}{|c|c|c|c|c|}
\hline \multirow{2}{*}{ Molecular formula } & \multicolumn{2}{|c|}{ Control } & \multicolumn{2}{|c|}{ Consortium } \\
\hline & RT & \% Area & RT & \% Area \\
\hline $\mathrm{C}_{9} \mathrm{H}_{18}$ & 2.83 & 5.047 & & \\
\hline $\mathrm{C}_{9} \mathrm{H}_{16} \mathrm{O}$ & 5.45 & 1.672 & & \\
\hline $\mathrm{C}_{10} \mathrm{H}_{16} \mathrm{O}$ & 6.2 & 6.79 & & \\
\hline $\mathrm{C}_{10} \mathrm{H}_{18}$ & 6.83 & 3.731 & & \\
\hline $\mathrm{C}_{11} \mathrm{H}_{16}$ & 7.67 & 2.753 & & \\
\hline $\mathrm{C}_{11} \mathrm{H}_{20}$ & 8.75 & 2.963 & 8.8 & 0.728 \\
\hline $\mathrm{C}_{11} \mathrm{H}_{18} \mathrm{O}$ & 10.58 & 3.887 & & \\
\hline $\mathrm{C}_{13} \mathrm{H}_{24}$ & 11.83 & 2.649 & 11.5 & 1.975 \\
\hline $\mathrm{C}_{14} \mathrm{H}_{16}$ & 13.43 & 3.634 & & \\
\hline $\mathrm{C}_{14} \mathrm{H}_{28}$ & 14.02 & 5.148 & 14.3 & 3.763 \\
\hline $\mathrm{C}_{14} \mathrm{H}_{30}$ & 16.13 & 2.044 & & \\
\hline $\mathrm{C}_{16} \mathrm{H}_{18}$ & 16.83 & 6.158 & 17.02 & 6.184 \\
\hline $\mathrm{C}_{15} \mathrm{H}_{30} \mathrm{O}$ & 18.53 & 3.770 & & \\
\hline $\mathrm{C}_{16} \mathrm{H}_{30} \mathrm{O}$ & 19.92 & 1.892 & 19.57 & 7.684 \\
\hline $\mathrm{C}_{17} \mathrm{H}_{36}$ & 21.43 & 0.930 & & \\
\hline $\mathrm{C}_{18} \mathrm{H}_{38}$ & 22.32 & 2.614 & 22 & 9.085 \\
\hline $\mathrm{C}_{19} \mathrm{H}_{38}$ & 23.97 & 4.222 & 24.37 & 14.497 \\
\hline $\mathrm{C}_{20} \mathrm{H}_{42}$ & 25.9 & 2.382 & & \\
\hline $\mathrm{C}_{18} \mathrm{H}_{36} \mathrm{O}_{2}$ & 26.93 & 2.961 & 26.53 & 12.437 \\
\hline $\mathrm{C}_{19} \mathrm{H}_{40}$ & 27.72 & 4.194 & & \\
\hline $\mathrm{C}_{19} \mathrm{H}_{32} \mathrm{O}_{2}$ & 28.58 & 1.524 & & \\
\hline $\mathrm{C}_{20} \mathrm{H}_{42}$ & 29.7 & 5.387 & 30.6 & 7.786 \\
\hline $\mathrm{C}_{21} \mathrm{H}_{44}$ & 31.6 & 6.475 & 32.52 & 6.610 \\
\hline $\mathrm{C}_{22} \mathrm{H}_{46}$ & 33.38 & 5.020 & 34.32 & 5.725 \\
\hline $\mathrm{C}_{23} \mathrm{H}_{48}$ & 35.07 & 3.421 & & \\
\hline $\mathrm{C}_{24} \mathrm{H}_{50}$ & 36.7 & 1.832 & & \\
\hline $\mathrm{C}_{25} \mathrm{H}_{52}$ & 38.32 & 1.164 & 39.32 & 2.584 \\
\hline $\mathrm{C}_{26} \mathrm{H}_{54}$ & 39.85 & 0.556 & 40.85 & 1.755 \\
\hline $\mathrm{C}_{27} \mathrm{H}_{56}$ & 41.35 & 0.633 & & \\
\hline $\mathrm{C}_{28} \mathrm{H}_{58}$ & 42.87 & 0.718 & & \\
\hline $\mathrm{C}_{29} \mathrm{H}_{60}$ & 44.6 & 0.556 & 45.22 & 0.669 \\
\hline $\mathrm{C}_{30} \mathrm{H}_{62}$ & 46.73 & 0.446 & 46.58 & 0.551 \\
\hline $\mathrm{C}_{35} \mathrm{H}_{70} \mathrm{O}$ & 49.22 & 0.335 & & \\
\hline $\mathrm{C}_{36} \mathrm{H}_{74} \mathrm{O}_{2}$ & 52.67 & 0.779 & & \\
\hline
\end{tabular}


Fig.1 Based on sequence homology and phylogenetic analysis, the fungal culture (a) K-08 was found to be Aspergillus sp., (b) K-12 as Aspergillus terreus (c) K-25 as Aspergillus aculeatus (d) K-43 as Scedosporium boydii.
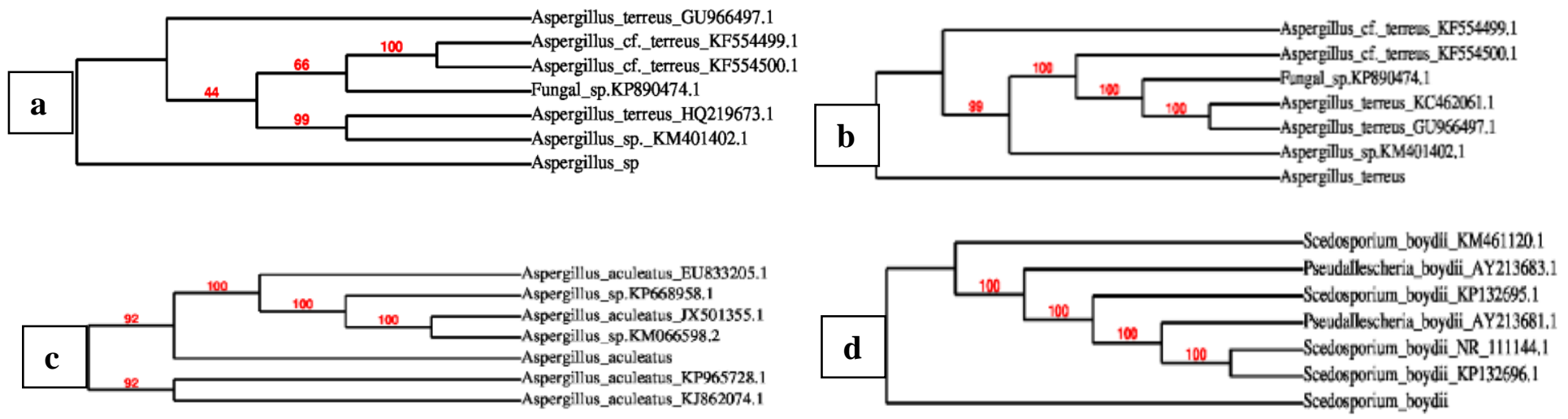

Fig.2a,b,c The Degradation of Crude oil and PAHs using fungal consortium.

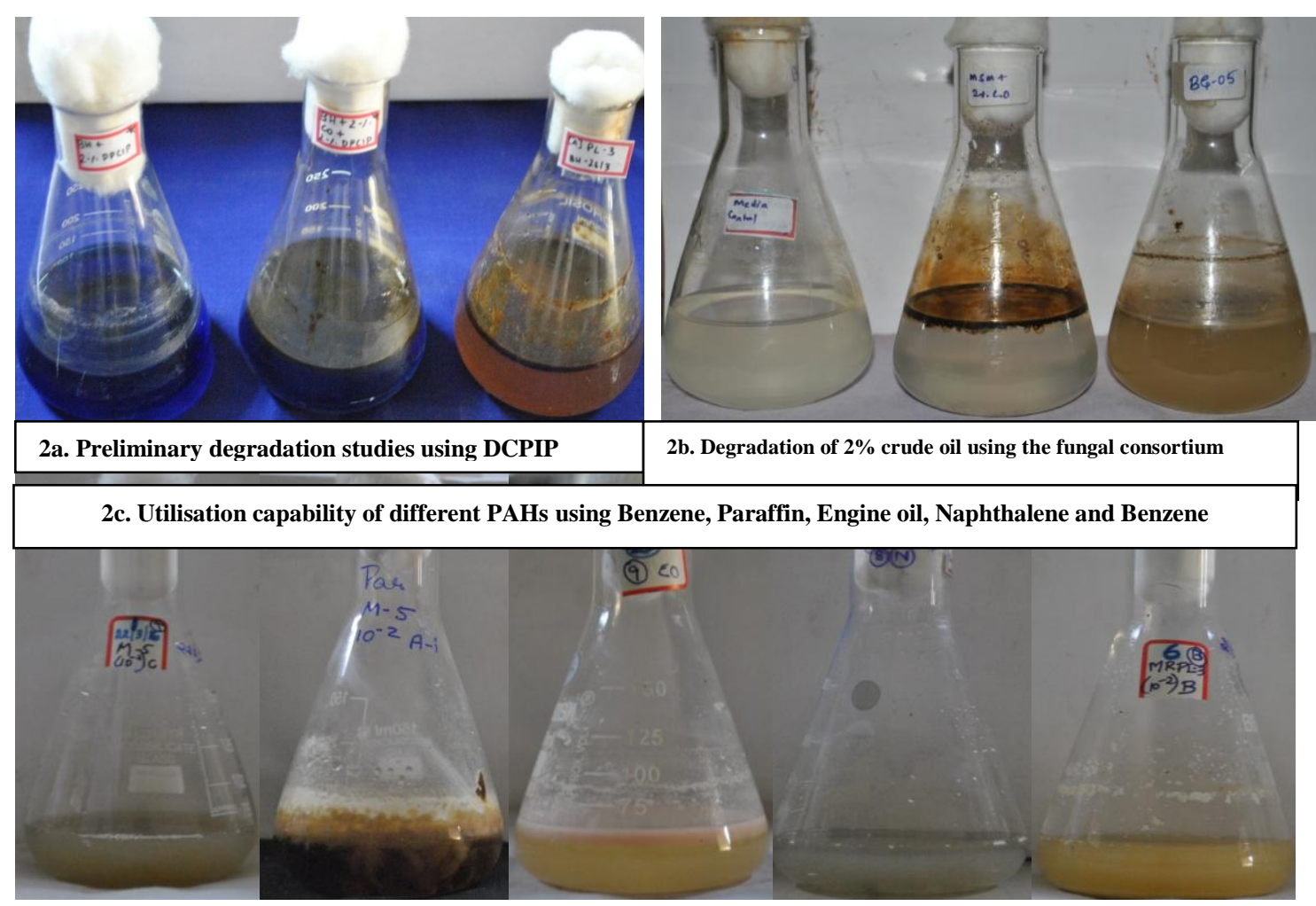


Fig.3 \% of TPH for residual components left after 10th day.

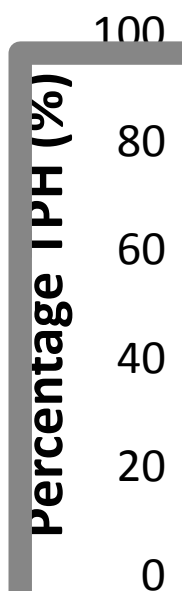

Fig.4 GC-MS showing different hydrocarbon contents of crude oil (Control) and after the treatment with consortium after 10th day.

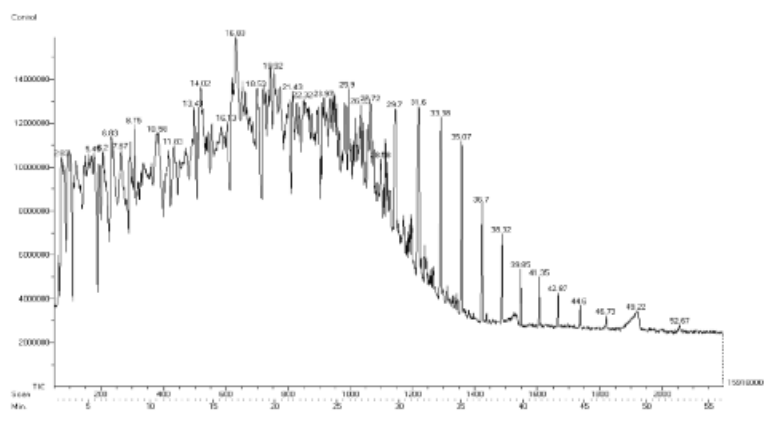

GCMS studies

From the GCMS analysis, it was observed that, all the 4 potent fungal strains are capable of degrading around 13 components of Crude oil completely. Most of the species show stable degradation of lower fractions i.e. $\mathrm{C}_{9}$ to $\mathrm{C}_{11}$ compounds, with the exception of $\mathrm{K}-43$ strain. After that, there is a varying degree of degradation exhibited by the species. But all the species show the degradation of the highest fraction i.e. $\mathrm{C}_{36} \mathrm{H}_{74} \mathrm{O}_{2}$ which was present in the control. It may be due to the degradation of hydrocarbons by the production of biosurfactants or dehydrogenase enzyme production, that assist in the total

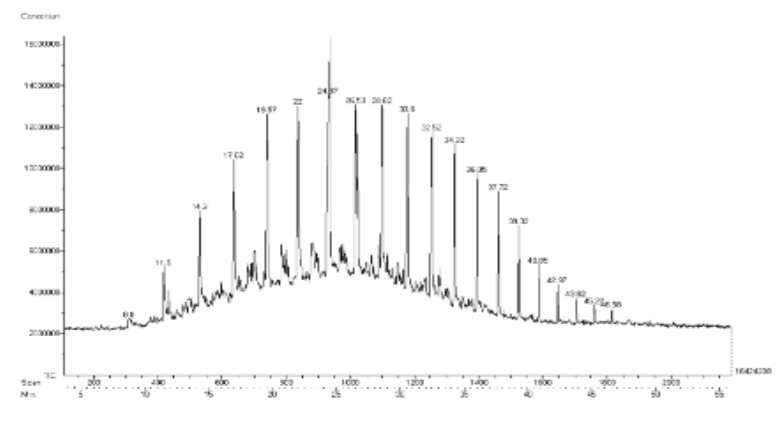

degradation of various components of crude oil fraction (Fig. $4 \&$ Table-2). Baker and Herson (1994) reported that degradation of hydrocarbons with long chains from C 18 to C25 proceeds only slowly. In this context isolation of a bacterium capable of degrading complex hydrocarbon is highly useful in the bioremediation of hydrocarbon polluted areas. This result indicated that branched alkanes, alkene, and alkylnaphthalenes were thoroughly degraded. However, linear alkanes chains, hopanes, and steranes were still remaining in the soil. In addition, the longer $n$-alkane chains were degraded with relatively higher rate, leaving the shorter part of the n-alkane as the residual fraction at the end of the 
bioremediation test. Moreover, it was observed that the concentration of residual $n$-alkane (short chains) decreased as the inoculation volume increased.

In conclusion, the present study reveals the potency of the fungal isolates from different localities of west coast of Karnataka, to degrade PAHs and crude oil components. The prepared consortium was having the capability of utilizing the components of the crude oil and converts into less toxic components. Further off the optimization of process parameters, biosurfactant screening and immobilization studies need to undertake to enhance the degradation in both ex-situ and in-situ environment using the developed consortium.

\section{Acknowledgement}

We would like to thank, Karnataka State Council for Science and Technology (KSCST-KSBDB- IISc), Bengaluru for financial assistance (Project No. 39S-B-BE098). We would like to sincerely thank to Sophisticated Analytical Instrument Facility (SAIF) center, IIT Madras for GC-MS facility, MRPL for soil sampling and Management, and Head Dept. of Biotechnology, The Oxford College of Engineering for the infrastructure \& encouragement.

\section{References}

Al-Nasrawi, Hussain, 2013. Biodegradation of crude oil by fungi isolated from Gulf of Mexico. J. Bioremed. Biodegrad., 3(4): 1-6.

Antizar-Ladislao, Blanca Joe, Lopez-Real, Angus James Beck. 2006. Degradation of polycyclic aromatic hydrocarbons (PAHs) in an aged coal tar contaminated soil under in-vessel composting conditions. Environ. Pollu., 141: 459-468.

Baker, K.H. 1994. Bioremediation of surface and subsurface soils, in: Baker KH, Herson DS (eds), Bioremediation. McGraw-Hill, Inc., pp. 209-259.

Balaji, V., Arulazhagan, P., Ebenezer P. 2014. Enzymatic bioremediation of polyaromatic hydrocarbons by fungal consortia enriched from petroleum contaminated soil and oil seeds. $J$. Environ. Biol., 35: 1-8.

Bisht, S., Piyush, P., Bhavya, B., Shivesh, S., Vivek, K., Krishan, D., Sharma. 2015. Bioremediation of polyaromatic hydrocarbons (PAHs) using rhizosphere technology. Brazilian J. Microbiol., 46(1): 7-21.

Chandran, P. and Das, N. 2011. Microbial Degradation of Petroleum Hydrocarbon Contaminants: An Overview. Biotech. Res. Int., 941810 , $1-13$.

Chaudary, S., Jyothi, L., Vandana, S. 2012. Assessment of Diesel degrading potential of fungal isolates from sludge contaminated soil of petroleum refinery, Haryana. Res. J. Microbiol., 7(3): 182-190.

Dasari, S., VenkataSubbaiah, K.C., Rajendra, Lokanatha, V. 2014. Biosurfactant-Mediated

Biodegradation of Polycyclic Aromatic HydrocarbonsNaphthalene. Bioremed. J., 18: 258265.

George-Okafor, U., Floretta, T., Florence, M.O. 2009. Hydrocarbon degradation potentials of Indigenous fungal isolates from petroleum contaminated soils. Int. J. Physical and Natural Sci., 3(1): 1-6.

Hadibarata, T. and S. Tachibana. 2009. Microbial degradation of n-eicosane by filamentous fungi. In: 
Interdisciplinary studies on environmental chemistry and environmental research in Asia. (Eds. Y. Obayashi, T. Isobe, A. Subramanian, S. Suzuki and S. Tanabe), Terrapub, Tokyo, pp. 323329.

Igiehon, O., Nicholas. 2015. Bioremediation Potentials of Heterobasidionannosum 13.12B and Resiniciumbicolor in Diesel Oil Contaminated Soil Microcosms. J. Appl. Sci. Environ. Manage, 19(3): 513-519.

Jimenez, N., Morris, B.E.L., Cai, M,. Grundger, F., Yao, J., Richnow, H.H., Kruger, M. 2012. Evidence for in situ methanogenic oil degradation in the Dagang oil field. Org. Geochem., 52: 44-54.

Karimi, P., Normala, B.H., Mohammad, P.Z. 2015. Sequential Preconditioning and Its Effect on Crude Oil Bioremediation by Indigenous Soil Bacteria. Int. J. Scientific Res. in Environ. Sci., 3(10): 0357-0369.

Kumar, B.L., Sai Gopal, D.V.R. 2015. Effective role of indigenous microorganisms for sustainable environment. Biotech., 5: 867-876.

Kumar, P.S.V. and Manjunatha, B.K. 2015. Studies on Hydrocarbon Degradation by the Bacterial Isolate Stenotrophomonas rhizophila (PM-1) from the oil spilled regions of Western Ghats of Karnataka. Sci. Technol. ARTS Res. J., 4(3): 139-144.

Manilal, V.B. and Alexander, M. 1991. Factors affecting the microbial degradation of phenanthrene in soil". Appl. Microbiol. Biotech., 35: 401405.

Margesin, R., Labbe, D., Schinner, F., Greer, C.W., Whyte, L.G. 2003. Characterization of hydrocarbondegrading microbial populations in contaminated and pristine Alpine soils. Appl. Environ. Microbiol., 69(6): 3085-92.

Nwachukwu, S.C.W. 2000. Enhanced rehabilitation of tropical aquatic environments polluted with crude petroleum using Candida utilis. J. Environ. Biol., 21(3): 241-250.

Obahiagbon, K.O., Agbonghae, E.O., Amenaghawon, N.A. 2014. Effect of microbial load of Aspergillus niger and Pseudomonas aeruginosa on the bioremediation of crude oil polluted water". J. Material Environ. Sci., 5(6): 1786-1791.

Obayori, O.S., Ilori, M.O., Adebusoye, S.A., Oyetibo, G.O., Omotayoand, A.E., Amund, O.O. 2009. Degradation of hydrocarbons and biosurfactant production by Pseudomonas sp. Strain LP-1. World J. Microbiol. Biotechnol., 25: 1615-1623.

Pasumarthi, R., Chandrasekaran, S., Mutnuri, S. 2013. Biodegradation of crude oil by Pseudomonas aeruginosa and Escherichia fergusonii isolated from the Goan coast. Marine Poll. Bull., 76: 276282.

Potin, O., Catherine, R., Eti-enne, V. 2004. Bioremediation of aged polycyclic aromatic hydrocarbons (PAHs)contaminated soil by filamentous fungi isolated from the soil. Int. Biodeterioration \& Biodegrad., 54: 45-52.

Rahman, K.S.M., Thahira-Rahman, J., Lakshmana perumalsamy, P., Banat, I.M. 2002. Towards efficient crude oil degradation by a mixed bacterial consortium. Biores. Technol., 85(3): 257-261.

Rushton, D.G., Ghaly, A.E., Martinell, K. 2007. Assessment of Canadian Regulations and Remediation Methods for Diesel Oil Contaminated 
Soils. American J. Appl. Sci., 4(7): 465-478.

Sayara, T., Eduard, B., Gloria, C., Montserrat, S., Antoni, S. 2011. Bioremediation of PAHscontaminated soil through composting: Influence of bioaugmentation and biostimulation on contaminant biodegradation. Int. Biodeterioration \& Biodegrad., 65: 859-865.

Senthilkumaran, R. and Sivakumar, T. 2015. Biodegradation of fungi isolated from Marine Ecosystem. Int. J. Adv. Res. Biol. Sci., 2(11): 312-318.

Stephen, E., Loretta, O.O. and Augustine, O.I. 2015. Bioremediation of mechanic workshop polluted soil amended with poultry litter. Biosci Res. in Today's World, 1(1): 77-83. Vanishree, M., Thatheyus, A.J., Ramya, D. 2014. Biodegradation of petrol using fungus Penicillium sp. Sci. Int., 2(1): 26-31.

Weissenfels, W.D., Klewer, H.J., Langhoff, J. 1992. Adsorption of polycyclic aromatic hydrocarbons (PAHs) by soil particles: influence on biodegradability and biotoxicity. Appl. Microbiol. Biotechnol., 36: 689-696.

Youssef, M., El-Taweel, G.E., El-Naggar, A.Y. 2010. Hydrocarbon degrading bacteria as indicator of petroleum pollution in Ismailia canal, Egypt, World Appl. Sci. J., 8(10): 12261233.

\section{How to cite this article:}

Praveen Kumar, S.V., B.K. Manjunatha, Pavani Bhat, R. Veena, Swetha S. Pawate and Yogashree, M. 2016. Bioremediation of Poly Aromatic Hydrocarbons (PAHs) and Crude Oil by Fungal Consortium from West Coast of Karnataka. Int.J.Curr.Microbiol.App.Sci. 5(10): 386-396. doi: http://dx.doi.org/10.20546/ijcmas.2016.510.044 